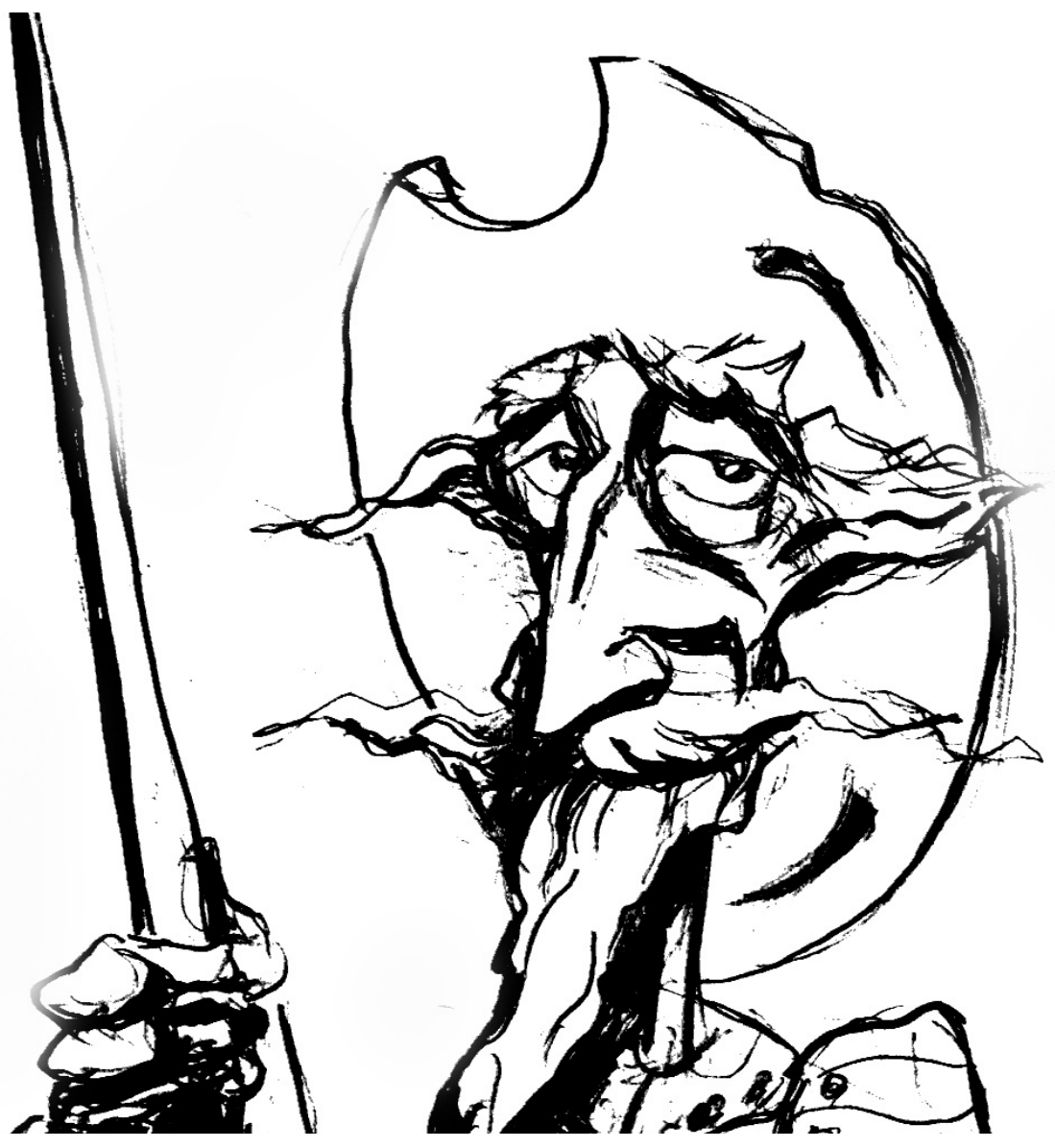

La CGT de los Argentinos: un espacio de confluencia combativa en el contexto del onganiato

[Valeria Caruso] 



\section{La CGT de los Argentinos: un espacio de confluencia combativa en el contexto del onganiato*}

\section{The CGT de los Argentinos: a Space of Combative Confluence in the Context of the Onganiato}

VALERIA CARUSO

Resumen

El propósito de este artículo es analizar a la Confederación General del Trabajo de los Argentinos (CGTA) como un espacio de confluencia de actores y demandas que excedieron lo estrictamente gremial. En primer lugar, se examinan los componentes asociativos existentes en el sindicalismo argentino que posibilitaron la conformación de esta central obrera como articuladora de la oposición política a la autodenominada "Revolución Argentina". En segundo lugar, a partir del examen de un conjunto amplio de fuentes, se indagan las condiciones de posibilidad de esta experiencia, sus características y limitaciones.

\section{Palabras clave}

CGT de los Argentinos; Sindicalismo Combativo; Onganiato.

\begin{abstract}
Abstrac
The purpose of this article is to analyze the General Confederation of Argentine Labor (CGTA) as a space of confluence of actors and demands that exceeded the strictly union. In the first place, the associative components existing in Argentine trade unionism that made possible the formation of this labor union as an articulator of the political opposition to the self-styled "Argentine Revolution" are examined. Second, based on the examination of a wide range of sources, the conditions of possibility of this experience, its characteristics and limitations are investigated.
\end{abstract}

Key words

CGT de los Argentinos; Combative Unionism; Onganiato.

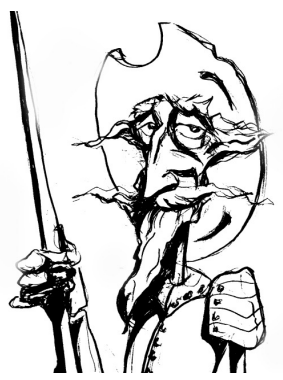

Recibido con pedido de publicación el 10 de octubre de 2020

Aceptado para su publicación el 31 de enero de 2021

Versión definitiva recibida el 2 de marzo de 2021

Valeria Caruso, Consejo Nacional de Investigaciones Científicas y Técnicas, Universidad de Buenos Aires, Buenos Aires, Argentina; e-mail: caruso.valeria@gmail.com

\footnotetext{
* Agradezco las sugerencias de los evaluadores anónimos de la revista

Esta obra se publica bajo licencia Creative Commons. Atribución-NoComercial-CompartirIgual 4.0 Internacional
}

Caruso, Valeria "La CGT de los Argentinos: un espacio de confluencia combativa en el contexto del onganiato", Prohistoria, Año XXIV, núm. 35, jun. 2021, pp. 163 - 189 
"La CGT de los Argentinos fue realmente un crisol político que preanunciaba todo lo que vendría después en la Argentina. [...] No se entiende lo que paso después sin esa experiencia." (Vertbitsky, 2018: 62).

\section{Introducción}

Las afirmaciones con la que se inicia esta indagación son ilustrativas de la relevancia que en las memorias de militancia setentista se le otorga a la experiencia que se desarrolló en torno a la Confederación General del Trabajo de los Argentinos (CGTA), iniciada en marzo de 1968. Esa significación no solo fue señalada por personas que, como Vertbitsky, tuvieron una activa participación en esa central obrera, ${ }^{1}$ sino también por personalidades de la cultura argentina como Beatriz Sarlo (2014) que, lejos de identificarse con el peronismo, destacan el lugar de esa CGT en su juventud. En esa línea también pueden situarse recientes trabajos historiográficos sobre el proceso de "peronización" de estudiantes universitarios, en los que es resaltado el rol de ese ámbito como espacio de socialización política (Friedemann, 2014; Dip, 2017; Manzano, 2017). La recurrente mención sobre la centralidad de la CGTA como espacio de iniciación política nos condujo a preguntarnos acerca de las razones por las cuales esta experiencia resultó sustantiva para tantos hombres y mujeres a fines de la década del '60.

Diversos aspectos de la CGTA han sido abordados en investigaciones de diferente alcance. Los trabajos de Daniel James (1990), Patricia Berrotarán y Pablo Pozzi (1994), James Brennan (1996), Julio Godio (2000), Mónica Gordillo (2003), Alejandro Schneider (2005) y Darío Dawyd (2008; 2011), respectivamente, han abordado el estudio de esta central sindical desde perspectivas en las que se enfatiza su representatividad para la clase obrera argentina. Las investigaciones de Cristina Viano (1994), Oscar Anzorena (1998), Juan A. Bozza (2001; 2009), Julieta Bartoletti (2011) y Luciana Sotelo (2012) han explorado distintas conexiones de esta CGT con organizaciones vinculadas a la izquierda peronista durante el período. No obstante, consideramos que aún resta indagar acerca de los componentes asociativos propios del sindicalismo argentino que le permitieron a la CGT de los Argentinos impulsar y articular la organización de distintos sectores sociales por fuera de lo estrictamente sindical.

De allí que nuestro objeto sea analizar las condiciones de posibilidad de

\footnotetext{
${ }^{1}$ Recordemos que Vertbitsky se desempeñó como jefe de redacción del Semanario CGT, órgano de prensa de esta central obrera.
} 
la CGTA como espacio de confluencia de actores y demandas que excedieron lo estrictamente gremial. En relación con esta cuestión, nuestra hipótesis es que la CGT de los Argentinos devino un espacio de articulación política y social porque condensó la necesidad de elaborar nuevas formas de intervención en un contexto clausurado para actuar dentro de los marcos de representación partidaria e institucional tradicionales.

A lo largo del trabajo se verá que la construcción del corpus documental aquí utilizado, intentó recoger diferentes fuentes documentales: entrevistas, prensa periódica de la época como Informes DIL, 1ํ Plana, La Razón, La Prensa y Crónica, el órgano de prensa de esta central, el Semanario CGT, intercambios epistolares, entre otros, que posibilitará el análisis de esta experiencia tal como se plantea en los siguientes apartados. En primer término, exploraremos las transformaciones que se dieron en el sindicalismo argentino desde 1955, y que actuaron como antecedentes de las características que adoptó la CGTA en 1968. En segundo lugar, examinaremos el proceso formativo de la CGT "Paseo Colón" como articuladora del "frente civil de resistencia" a la dictadura presidida por Juan Carlos Onganía. Posteriormente, indagaremos las características de esta iniciativa y las limitaciones de sus proyecciones políticas. Finalmente, concluiremos realizando un balance de esta experiencia.

\section{Los antecedentes}

Tras el derrocamiento de Juan Domingo Perón en 1955, se inició en la Argentina un proceso de reformulación de las prácticas y de los discursos de aquellos sujetos que se identificaron con el peronismo. La irrupción de la autodenominada "Revolución Libertadora" marcó el inició de un ciclo donde la condición para la existencia de la política estuvo determinada por la exclusión del peronismo del sistema político. La puesta en vigencia en 1956 del decretoley 4.161 formalizaba la prohibición del Partido Justicialista y penaba el uso de la simbología peronista. Contrariamente al efecto buscado, la normativa terminó por desencadenar la confrontación entre quienes imponían las prohibiciones desde el poder del Estado y amplios sectores de la sociedad argentina que, a pesar de las proscripciones, persistían en su adhesión al peronismo. Esta cuestión actuó sobre la imposibilidad de los gobiernos que se sucedieron entre 1955 y 1973 de generar los consensos sociales necesarios para legitimar sus acciones e, indirectamente, fomentaron el funcionamiento de canales heterodoxos a través de los cuales la sociedad civil expresó su malestar político y social. ${ }^{2}$

\footnotetext{
2 Por "sociedad civil" nos referimos a instituciones e individuos que persiguen fines particulares. Sus demandas interpelan al Estado. En tanto que el concepto de "sociedad
} 
A partir de entonces comenzaron a definirse nuevas prácticas que apuntaban a la vigencia del peronismo como respuesta a la imposibilidad de participar dentro de los canales instituidos para la mediación política por el sistema democrático. Esas prácticas contribuyeron a reafirmar la presencia del peronismo en la escena pública argentina, reconfigurándose en los resquicios institucionales habilitados por el sistema legal.

En este marco de situación -que se prolongó durante dieciocho años- se fueron redefiniendo progresivamente las funciones y fines de instituciones que no necesariamente se inscriben en el ámbito de la sociedad política. En ese contexto es posible situar la reconfiguración de la función de los sindicatos argentinos durante el período abierto por la proscripción del peronismo. Al respecto, Juan Carlos Torre (2004) señala que "Las reiteradas proscripciones recaídas sobre el peronismo llevaron a los sindicatos a desempeñar, junto con la propia defensa de los trabajadores, la función, sui generis de representarlos también en sus lealtades políticas". De allí que el aumento de la injerencia del sindicalismo en la esfera política argentina resultó, al menos en parte, de la persistente imposibilidad de los sucesivos gobiernos de erradicar en amplios sectores de la clase obrera su adhesión al peronismo.

Otro de los elementos que incidió en la reconfiguración del sindicalismo como actor político fue la modalidad con la que se llevó adelante la paulatina normalización de la actividad gremial. El restablecimiento de la ley 14.455 de Asociaciones Profesionales en noviembre de 1958, estructuró los lineamientos formales sobre los cuales se desarrolló la actividad sindical. ${ }^{3}$ Daniel James (1990) afirma que la puesta en vigencia de esta normativa, además de redefinir las relaciones entre los sindicatos y el Estado, habilitó los canales que posibilitaron la conformación de un "poder sindical". Es decir, al tiempo que dotó al Estado de los medios para articular las relaciones con el mundo del trabajo, generó dispositivos que permitieron la acumulación de poder en las direcciones sindicales en detrimento del pluralismo sindical y la democracia de base.

Esta última cuestión, actúo sobre la potestad de las cúpulas sindicales para presionar a los gobiernos en pos de la consecución de reivindicaciones laborales para sus representados e, indirectamente, habilitó el resquicio institucional desde el cual estas pudieron articular la lucha por la vigencia del

política" refiere a instituciones e individuos con vocación a intervenir en la dirección del Estado o de transformarlo (Acha, 2004).

3 La ley 14.455 establecía la existencia legal de un sindicato único por industria, en contraposición al decreto sancionado por la dictadura de Aramburu en 1956 que preveía la creación de varios sindicatos por rama. Además otorgaba la personería jurídica a una sola central obrera. Al respecto, véase Gordillo (1996). 
peronismo. $^{4}$

Por otro lado, las mediaciones que los líderes sindicales estaban en condiciones de establecer con la clase obrera, con el movimiento peronista y con el Estado, los convirtió en cuadros políticos con injerencia en los asuntos públicos como ninguna otra organización vinculada al líder exiliado. Las relaciones que se configuraron entre estos actores se modificaron en función de las tensiones que acarrearon los cambios políticos y económicos que se presentaron durante el período.

En 1966 las contradicciones que engendraba el sistema de representación política en la Argentina alcanzaron su punto culminante. El marco de prohibición política creado por la autodenominada "Revolución Argentina" impedía expresar la conflictividad social que la propia dictadura generaba con la puesta en marcha de su plan de gobierno. El presidente de facto, el Teniente General Juan Carlos Onganía impulsó un programa tendiente a la consolidación de la industria dinámica con financiación del capital extranjero, el cual precisaba de una serie de medidas que impactaban sobre los salarios y las condiciones de trabajo de las actividades consideradas "ineficientes" de la economía local. En pos de la realización de su programa económico, la dictadura justificaba la suspensión de toda actividad y organización política como condición necesaria para el disciplinamiento social que, una vez logrado, posibilitaría la emergencia de un "tiempo político" (O'Donnell, 1996).

La puesta en marcha de plan del económico impulsado por la dictadura incidió en la profundización de la crisis que atravesaba el sindicalismo argentino, en tanto el desempleo, el congelamiento de los salarios, y la racionalización de la producción, incrementaban la presión sobre los representantes sindicales argentinos ahora impotentes para negociar con el gobierno de facto las condiciones de trabajo y salarios.

En ese cuadro de situación, se estructuraron tres tendencias sindicales. Por un lado, la participacionista, denominada Nueva Corriente de Opinión liderada por José Alonso (vestido), Rogelio Coria (construcción) y Juan José Taccone (Luz y Fuerza)-, predispuesta a cooperar con el gobierno en tanto este reconociera y colaborase con sus sindicatos. En una situación intermedia respecto a las políticas estatales se desplegaba la estrategia del sindicalismo "colaboracionista" adoptada por Augusto Vandor, máximo referente de la Unión Obrera Metalúrgica. ${ }^{5}$ Esta se caracterizaba por su disposición a dialogar con el Estado, pero manteniendo una posición crítica respecto a la política

\footnotetext{
${ }^{4}$ En la ley de Asociaciones Profesionales no se hacía mención o prescripción alguna sobre la posibilidad de que en los sindicatos se desarrollaran actividades políticas.

${ }^{5}$ Esta tendencia también fue conocida como "vandorismo", en referencia a la centralidad del liderazgo de Augusto Vandor en el movimiento sindical.
} 
económica implementada por la dictadura. Ambos lineamientos se dirimían entre la tensión que anidaba su proceder con el Estado y las reivindicaciones que reclamaban para sus representados. La decisión de no enfrentar abiertamente los planes de racionalización económica ponía en cuestión su capacidad de liderazgo y de representación de las bases gremiales sobre las cuales sustentaban su poder. Esta cuestión incidió en el fortalecimiento de la tendencia combativa que promovía la oposición frontal al gobierno dictatorial. En ella convergían sindicalistas identificados con el peronismo ortodoxo, como diversas tendencias de izquierda $\mathrm{y}$, en un primer momento, los sindicatos intervenidos por la dictadura. Esta tendencia sindical proyectaba la transformación de las estructuras políticas y economías de la sociedad argentina, junto con la defensa del patrimonio nacional a través de la activa participación del movimiento obrero organizado, tal como se había formulado en los programas de La Falda (1957) y Huerta Grande (1962).

La impotencia de la estrategia sindical imperante hasta entonces, junto con el incremento de la represión estatal, generaron las condiciones para reactualizar el bagaje presente en el sindicalismo combativo en la conformación del proyecto antidictatorial que se articuló en torno a la CGT de los Argentinos.

\section{Los comienzos}

El Congreso Normalizador de la CGT se desarrolló durante los últimos días del mes de marzo de $1968 .{ }^{6}$ La dictadura dilató la convocatoria con la intención de asegurar la victoria de una CGT complaciente con los planes de gobierno. Los líderes sindicales representantes del vandorismo y con la Nueva Corriente de Opinión no se presentaron. Especularon con la falta de quórum y la inhabilitación de los gremios intervenidos por la dictadura para participar en los comicios. No obstante, los 239 delegados asistentes resultaron suficientes para la realización de los comicios en los que resultó ganadora la única lista que se presentó a la elección, integrada por sindicalistas vinculados con el ala combativa que desde hacía años se encontraba en una posición marginal respecto a la dirección del movimiento obrero organizado. Resultaron electos para comandar la CGT: Raimundo Ongaro (FGB) como secretario general; Amancio Pafundi (UPCN) como secretario general adjunto; Patricio Datarmini (municipales de Capital Federal) secretario de Hacienda; Enrique Coronel (LF) como pro secretario de Hacienda; Julio Guillán (FOETRA) como Secretario de Gremial e Interior; Benito Romano (FOTIA) como Prosecretario Gremial e Interior; Ricardo de Luca (navales) como secretario de Prensa, Cultura, Propaganda y Actas; y Antonio Scipione (UF) como secretario de Previsión

\footnotetext{
${ }^{6}$ Informes DIL, marzo de 1968, pp. 20-21; "Gremios: La división de la CGT", Primera Plana, 2/04/68, pp. 12-13.
} 
Social. ${ }^{7}$

Quienes integraron la nueva cúpula sindical plantearon, desde el mismo momento de su asunción, la necesidad de articular la defensa de los derechos de los trabajadores en oposición a los otros dos liderazgos sindicales. Pero, además, buscaron estrechar vínculos con otras fuerzas sociales también avasalladas por las medidas implementadas por el gobierno de facto. ${ }^{8}$ Esta convocatoria se inscribía en el marco de las proyecciones que ya se venían elaborando en el interior del sindicalismo combativo para actuar en el contexto del onganiato. Así lo expresaba Amado Olmos en 1967:

¿Qué debemos hacer? Hay que reconstruirlo todo. Comenzar
desde abajo, abrir paso a los jóvenes militantes gremiales,
reestructurar a nivel de fábrica y barrio la organizaciones gremiales,
que, de ahora en más, no podrán ser separadas ni concebidas sino como
vanguardias de organizaciones más vastas en las que estén y en las
que confíen los sectores populares; organizar y promover a los
trabajadores y al pueblo del interior argentino; organizar y

${ }^{7}$ Informes DIL, cit., p. 22. Las tendencias participacionistas y dialoguistas se negaron a reconocer al nuevo secretariado, y un mes después celebraron su propio congreso en el cual se eligió Vicente Roqué (molineros, 62 leales) para dirigir el entramado sindical que se dio sede en la calle Azopardo. A partir de entonces, la fractura de la CGT marcó el inicio de una nueva etapa en la cual se profundizaron las diferencias entre las tres tendencias sindicales que impedirá la unidad del sindicalismo argentino hasta 1970.

8 Esta iniciativa no era una novedad dentro de las estrategias sindicales; basta remitirse a los postulados del plan de lucha de 1964 para observar la efectividad de esa estrategia.

9 Amado Olmos (1918-1968) inició su militancia sindical en el gremio de Sanidad en 1948, y años más tarde fue electo Secretario General de la Federación Argentina de Trabajadores de la Sanidad. En 1954 se desempeñó como diputado nacional del bloque peronista en calidad de "diputado obrero", liderando ese sector hasta el advenimiento del golpe de Estado de 1955, que lo confinó a la clandestinidad. Participó en el levantamiento de Valle. En 1958 fue designado como representante de las 62 organizaciones peronistas en el Comando Táctico Nacional creado por Perón y John W. Cooke durante la primera resistencia. Apoyó a Sebastián Borro en el conflicto desatado en el frigorífico municipal Lisandro de la Torre, y fue apresado en el marco del CONINTES. Fue uno de los promotores de la creación de la "Unión Popular" como alternativa electoral del peronismo en los comicios de 1962 que posibilitó el triunfo de líder textil Andrés Framini en las elecciones a gobernador en la provincia de Buenos Aires, que terminaron siendo anuladas por la presión ejercida por las Fuerzas Armadas. En tiempos del Plan de Lucha de la CGT del año 1964, Olmos acompañó desde su sindicato la estrategia de confrontación (Pulfer, 2018). Formó parte de la comisión directiva de la CGT que lanza el documento Hacia el cambio de estructuras. Bregó por el traslado de Perón a Cuba, siendo el emisario de las gestiones realizadas por Cooke para convencer al expresidente de la conveniencia de su traslado. Se opone al "vandorismo" desde las CGT "De pie junto a Perón" que lleva como secretario general a José Alonso. A fines del año 1967 Olmos se perfila como figura potable para ejercer la Secretaría General de la CGT, en el próximo Congreso Normalizador, a realizarse en marzo de 1968. 
promover la organización de los desocupados y de los sectores marginados de las villas miserias, organizándolo todo pero descentralizando y multiplicando los centros de organización. [...] No hay legalidad sino para algunos y para sus amos extranjeros. Volverá a haber legalidad para la Patria y para el pueblo cuando consigamos implantarla, pero ni un minuto antes." 10

Según el secretario del gremio de sanidad, los dirigentes sindicales debían constituirse en vanguardia del descontento de las bases obreras y de los sectores más golpeados por las medidas impuestas por la dictadura. Para Olmos los jóvenes militantes gremiales eran quienes debían articular la protesta social no desde las cúpulas sindicales, sino en las calles, y así disputar el poder del Estado.

El nuevo secretario general de la CGT se ajustaba al paradigma del “joven militante gremial" que Olmos clamaba para el proyecto del sindicalismo combativo. Hasta entonces Raimundo Ongaro era una figura relativamente nueva en el mundo gremial. ${ }^{11}$ Por otro lado, su candidatura para comandar la CGT, luego del fallecimiento de su referente histórico, ${ }^{12}$ surgió del consenso logrado entre dirigentes del sindicalismo combativo como Lorenzo Pepe, Antonio Scipione, Víctor Vázquez, y Julio Guillán, quienes buscaron que la dirección de la CGT fuera integrada por una persona que "equilibrara las disputas que se habían dado en el pasado" entre ellos, y que pudiera arribar acuerdos con los gremios independientes. ${ }^{13}$ La necesidad de consolidar acuerdos entre los dirigentes sindicales combativos resultó imprescindible para fortalecer la nueva conducción cegeteista frente a la CGT Azopardo.

Asimismo, resultaba sustancial lograr la adhesión de las distintas regionales sindicales al proyecto político y sindical que se articulaba en torno a la central con sede en la Avenida Paseo Colón. Para lo cual Ongaro emprendió, días después de haber sido electo secretario general de la CGT, una gira por distintas provincias con el objeto de conseguir los apoyos sindicales imprescindibles para el sostenimiento de la central combativa. Para la prensa

\footnotetext{
10 Olmos, Amado, "La autocracia sindical", en Cristianismo y Revolución, noviembre de 1967 (Baschetti, 1997: 248). Las cursivas son nuestras.

11 Ongaro alcanzó en 1966 la dirección de la Federación Gráfica Bonaerense derrotando electoralmente a la tendencia que hasta poco tiempo antes había liderado Riego Ribas (vinculado a los 32 gremios democráticos y al Partido Socialista). Hemos analizado la trayectoria política, sindical e intelectual de este dirigente gráfico en Caruso (2019).

${ }^{12}$ Recordemos que Olmos falleció dos meses antes de celebrarse el Congreso Normalizador del ' 68 en un accidente automovilístico. En su homenaje, los líderes sindicales que participaron del conclave cegetista acordaron bautizar el encuentro con su nombre.

${ }^{13}$ Entrevista a Carlos “Pacho" Gaitán, Buenos Aires, 13 de mayo de 2013.
} 
periódica conseguir esas adhesiones "los fortalecería mucho más que el simbólico apoyo de Juan Perón, los nacionalistas y el radicalismo." 14

Las líneas de continuidad de la CGTA con los lineamientos del sindicalismo combativo también pueden observarse en las primeras manifestaciones públicas realizadas por Ongaro al platear:

“Debe lucharse por el bienestar de todos los trabajadores junto a la juventud, los profesores universitarios, los maestros, los partidarios políticos a los que no se los considera disueltos y la Iglesia Católica [...] Al gobierno le decimos que el pueblo no lo quiere y que sus días están contados. [...] Nuestro frente de resistencia civil no acabará como otros, en la casa de gobierno."15

En esta alocución, la CGT es presentada como interlocutora de la sociedad frente a la dictadura, en tanto se propone desafiar las restricciones impuestas a partir de la conformación de un frente de resistencia civil. El dirigente gráfico retoma la idea de Olmos: proyectar la central obrera como vanguardia de los trabajadores, articulando la protesta social y política contra el gobierno de facto. Al mismo tiempo, desliza una promesa de intransigencia respecto a los detentores del poder estatal. Este posicionamiento repercutió rápidamente en dirigentes políticos de adscripciones partidarias opuestas al peronismo.

El 1ํ de abril de 1968; 72 horas después de que Ongaro fuera electo secretario general de la CGT, Raúl Alfonsín le hacía llegar una comunicación en la que manifestaba su adhesión al proyecto político de la central. En esa carta Alfonsín expresaba: "Ustedes han sido leales al mando de las bases y se colocaron junto al pueblo: las palabras suyas al cabo del Congreso de la CGT son testimonio de lo que es el pensamiento popular. La columna ya está en marcha y nada podrá detenerla. La meta es cada vez más cercana."16 La convergencia de dos dirigentes de extracciones políticas tan diversas, según Primera Plana, era una demostración de la coincidencia "en el pensamiento y en la acción con otra media docena de caudillos políticos, sindicales y militares; asociados lograron producir una eclosión opositora que buscó tumbar a Onganía." 17 Asimismo, la comunicación de Alfonsín a Ongaro también era leída como expresión de las tensiones existentes en el interior de la Unión Cívica Radical del Pueblo (UCRP), a raíz de las divergencias con los planes políticos que Ricardo Balbín pergeñaba - según el semanario- con sectores de las Fuerzas

\footnotetext{
14 “Tener y no tener", Primera Plana, 9/04/68, pp. 13-14.

${ }^{15}$ La Razón, 30/03/68, p. 6.

${ }^{16}$ Reproducida en "El Gobierno hostigado", Primera Plana, 9/04/68, pp. 12-13.

17 "El Gobierno hostigado", cit., p.13.
} 
Armadas para provocar un nuevo golpe que evidenciara el agotamiento de la gestión de Onganía. Lo cual estaba en abierta oposición a las intenciones de un sector importante de la dirigencia radical -integrado por la rama juvenil de la UCRP y la fracción liderada por el expresidente Arturo Illia- que buscaba sumarse al frente político y social que comenzaba a gestarse en la CGTA. ${ }^{18}$

La intención de ampliar la base de apoyo del frente civil de resistencia que desde la CGTA se intentaba forjar también se puso de manifiesto en los actos conmemorativos del $1^{\circ}$ de mayo que se desarrollaron en las ciudades de Córdoba, Mendoza, Rosario, Tucumán y San Justo (Pcia. de Buenos Aires) a pesar de estar prohibidos desde 1966. Según la crónica publicada en el Semanario CGT, asistieron a la convocatoria de Buenos Aires más de diez mil personas. Ricardo Illia, hermano del expresidente y exsecretario general de la presidencia hasta 1966, participó de la manifestación que se desarrolló en la localidad de San Justo. El cronista de Primera Plana decía ante su presencia: "hace dos años nadie lo hubiera imaginado en una manifestación de obreros; entonces, como ahora, no se autorizaba celebrar el 1ro de mayo."19 Estas manifestaciones representaban el primer intento de generar adhesiones por fuera del ámbito gremial, y explicitar su llamado a la sociedad a sumarse en la lucha por la "Liberación argentina", según expresaba Ongaro en el acto realizado en la ciudad de Córdoba. Agustín Tosco al inaugurar la convocatoria exclamaba: "Este es el acto del pueblo argentino contra el momento que vive el país." 20

Los actos conmemorativos del día del trabajador fueron acompañados de la publicación y difusión del Mensaje del $1^{o}$ de Mayo a través del primer número de su órgano de prensa. Allí, la conducción de la CGT “Paseo Colón” plasmaba sus objetivos en los siguientes términos:

"La CGT convoca en suma a todos los sectores, con la única excepción de minorías entregadoras y dirigentes corrompidos, a movilizarse en los cuatro rincones del país para combatir de frente al imperialismo, los monopolios y el hambre. Esta es la voluntad indudable de un pueblo harto de explotación e hipocresía, herido en su libertad, ofendido en sus sentimientos, pero dispuesto a ser el único protagonista de su destino. [...]

Porque no se puede encarcelar ni matar a todo el pueblo, y porque la inmensa mayoría de los argentinos, sin pactos electorales, sin aventuras colaboracionistas ni golpistas sabe

\footnotetext{
18 "A dónde va el gobierno", Primera Plana, 9/07 68, p. 14.

19 "La rebelión de las bases", Primera Plana, 7/05/68, p. 15.

20 Semanario CGT, núm. 2, 9/05/68, p. 3.
} 
que sólo el pueblo salvara al pueblo."21

Esta convocatoria buscaba generar la unidad social para oponerse a un gobierno que se arrogaba el poder del Estado en detrimento de los intereses generales. Pero además, en ella recidía el convencimiento de estar expresando los anhelos de una sociedad atravesada por la represión estatal e inhibida de los medios públicos e institucionales para tramitar la conflictividad social. ${ }^{22}$ Consideramos que este llamamiento a distintos sectores sociales a adoptar una actitud combativa frente a la dictadura fue uno de los factores que intervinieron en el crecimiento de las adhesiones que en los meses siguientes recibió el proyecto político articulado en torno a la $\mathrm{CGTA}^{23}$ el cual fue reforzado por otras acciones que se promovieron desde la central obrera. ${ }^{24}$

El Semanario CGT, ${ }^{25}$ dirigido por Rodolfo Walsh fue otro medio para generar adhesiones por fuera del ámbito sindical. ${ }^{26}$ Este periódico, además de funcionar como un vehículo comunicacional del sindicalismo combativo fue el nexo coordinante de una nueva generación de periodistas desde el cual denunciaron la complicidad de los propietarios de los medios de comunicación

\footnotetext{
${ }^{21}$ Semanario CGT, núm. 1, 1/05/ 68, p. 1.

${ }^{22}$ La dictadura puso en vigencia un conjunto de decretos/leyes tendientes a restringir las libertades civiles y políticas, como la 16.984 (prohibición de la propaganda comunista); 17.401/67(Ley Anticomunista); 17.649/67 (movilización militar de la población civil); 17.567/68 (represión a huelga de empleados públicos); 18.232/69 (expulsión de los extranjeros “indeseables"); 18.1119/68 (censura cinematográfica); 18.701/70 (pena de muerte para algunos delitos); 18.799/70(reducción de la figura del habeas corpus).

${ }^{23}$ Algunas de las organizaciones y movimientos que se expresaron en tal sentido fueron: Movimiento de la Juventud Radical, Movimiento Nacional Justicialista, Juventud Demócrata Cristiana (Comando Nacional), Partido Socialista Argentino (Comité Nacional), Partido Socialista de la Izquierda Nacional, Movimiento de Liberación Nacional, Unión Cívica Nacional del Pueblo (comité Provincia de Buenos Aires), periódico Azul y Blanco, Acción Sindical Argentina (comité Ejecutivo Nacional y delegaciones de Rosario y Santa Fe), 12 Organizaciones Únicas de Rosario, Villa Mercedes, Federación Universitaria de La Plata, Centro de Estudiantes de Derecho de Santa Fe, Agrupación de Derecho Integralista de Santa Fe, Centro de Estudiantes de Ciencias Médicas y de Ingeniería de Santa Fe, Agrupación Nacional de Estudiantes Peronistas, movimiento Revolucionario Peronista, Frente Peronista de Liberación (entre otras agrupaciones peronistas que se mencionan). Semanario CGT, núm.1, cit., p. 4.

${ }^{24}$ En otro trabajo (Caruso, 2015b) hemos analizado la confluencia en la CGTA de distintos colectivos intelectuales que por cuestiones de espacio no podemos tratar en el presente artículo. ${ }^{25}$ El Semanario CGT contó con 55 números publicados entre el $1^{\circ}$ de mayo de 1968 y febrero de 1970. Los cinco últimos números fueron publicados en la clandestinidad. Un análisis exhaustivo sobre este periódico puede consultarse en Caruso (2015).

${ }^{26} \mathrm{El}$ autor de Operación Masacre conoció a Raimundo Ongaro un mes en antes de que este fuera electo secretario general de la CGT, en la residencia madrileña en la que se asilaba Perón. Ese breve encuentro fortuito, puso en conocimiento uno de otro, y cuando finalmente el dirigente gráfico se hizo cargo de la cúpula cegeteista convocó al escritor para organizar el equipo encargado de la elaboración del órgano de prensa de la central.
} 
con la dictadura, y con las clases dominantes que la sustentaban. ${ }^{27}$ Asimismo, a través del Semanario se buscó difundir los fines y alcances del proyecto político de ese espacio sindical, y amplificar el cuestionamiento al gobierno militar y al accionar espurio de la burocracia sindical. De hecho, la publicación por entregas en el Semanario de la investigación realizada por Walsh sobre el asesinato de Rosendo García resaltaba el carácter "gansteril" del liderazgo sindical de Vandor, y los líderes de la CGT Azopardo, al mismo tiempo que subrayaba las diferenciales que los distanciaba de la dirigencia gremial de la central combativa. ${ }^{28}$

Asimismo, desde los primeros números del periódico se enfatizaba sobre la necesidad de expresar en las calles el malestar ocasionado por la dictadura. Según la crónica publicada en el Semanario CGT sobre los actos del día del trabajador impulsados por la central combativa, la asistencia a la convocatoria fue multitudinaria en Buenos Aires. ${ }^{29}$ Declaraba más tarde Pafundi, secretario adjunto de la CGTA, refiriéndose a los actos del 1ํ de Mayo: "Fuimos golpeados porque estábamos en la calle, no entre cuatro paredes. Es una satisfacción haber compartido la suerte de los trabajadores".

La intención de incentivar la movilización popular y de romper el enclaustramiento impuesto por la dictadura se puso también de manifiesto en las gestiones impulsadas por la conducción de la central obrera para conmemorar el segundo aniversario del derrocamiento del presidente radical Arturo Illia. Para lo cual, el secretario de la CGTA visitó distintas ciudades del interior del país, en las que se reunió con diversos colectivos políticos y sociales; no solo para ampliar la convocatoria a los actos programados para el 28 de junio, sino también para que se sumaran al proyecto político y sindical que se articulaba en la CGT Paseo Colón. Asimismo, con las visitas a las provincias se intentaba agrupar a los sectores afectados por las políticas dictatoriales, para así evidenciar su situación y sus reivindicaciones, y coordinar acciones conjuntas. La llegada de Ongaro durante el mes de junio de 1968, a los ingenios azucareros

\footnotetext{
${ }^{27}$ El grupo inicial conformado por Walsh estuvo integrado por Verbitsky en la jefatura de redacción, Rogelio García Lupo -quien había colaborado con Walsh en la creación de la agencia cubana Prensa Latina-, y Milton Roberts. Se sumaron las colaboraciones de José María Pasquini Durán, Hugo Rapopport, Luis Guagnini, Susana Viau, Silvia Rudni, Miguel Briante, Ignacio Ikonicoff, Jorge Bernetti, Carlos Aznáez, Victoria y Patricia Walsh (Ferreyra, 1997).

${ }^{28}$ ¿Quién mató a Rosendo? se publicó originalmente en seis entregas en el Semanario CGT, entre el 16 de mayo de 1968 y el 27 de junio de 1968. La investigación fue publicada como libro por la editorial Tiempo Contemporáneo, en 1969, un mes antes del Cordobazo. Acerca de las variaciones de las notas publicados en el Semanario respecto al libro, véase Dawyd (2012).

${ }^{29}$ Semanario CGT, núm.1, cit., p. 3. Además, se informaba acerca del accionar de las fuerzas de seguridad en la represión de los concurrentes a los actos que se realizaron en Tucumán y Rosario. La intervención de la policía en la ciudad bonaerense de San Justo terminó con un saldo de doscientos cuarenta detenidos. La Razón, 2/05/68, p. 4.
} 
en las provincias de Tucumán y Jujuy, ${ }^{30}$ como a los barrios de emergencia mendocinos tenía por objeto impulsar una "marcha de los pobres" de carácter nacional que dinamizara un "plan de acción en defensa de las conquistas sociales" cercenadas por el gobierno de facto. ${ }^{31}$

En las vísperas del acto que se desarrollaría en la ciudad de Córdoba, y que tendría como principales oradores a Illia y Ongaro, este último declaró: "nosotros consideramos que la Argentina, está invadida y ocupada por los enemigos del pueblo. Hoy, como en 1806 en ocasión de las invasiones inglesas, necesitamos superar nuestras diferencias para hacer frente al enemigo común de la Nación." ${ }^{32}$ La convocatoria lanzada tenía entonces por objeto repudiar la fractura de la orden institucional orquestada por las FFAA a las que además se consideraba como un "ejercito de ocupación" que actuaba en beneficio de intereses extranjeros antes que del bienestar general. De allí, que la analogía a las invasiones inglesas pueda ser leída tanto como un llamamiento a emular la acción popular que en el pasado expulsó a las fuerzas invasoras, como una expresión de deseo acerca de la potencia de la movilización como desestabilizadora del gobierno dictatorial.

Las manifestaciones en rechazo al golpe de Estado que puso fin al gobierno de Illia se desarrollaron el 28 de junio de 1968 en las ciudades de Buenos Aires, Rosario, Tucumán, La Plata y Mendoza, las cuales contaron con la adhesión de distintas agrupaciones políticas. ${ }^{33}$ En todas las ciudades donde las movilizaciones se llevaron adelante, el despliegue policial evitó que estas se realizaran como estaban previstas. Solo en Santiago del Estero se realizaron los actos sin incidentes.

No obstante, la presencia de Illia con Ongaro en la ciudad de Córdoba generó tensiones en el interior del partido Radical y del movimiento peronista.

\footnotetext{
30 "Preparan los actos del 28", Crónica, 14/06/68; “Medidas de seguridad se adoptaron en Salta ante la presencia del gremialista Ongaro para evitar alteraciones del orden público", La Razón, 19/06/68; “Llegó a Jujuy el Sr. Raimundo Ongaro”, La Prensa, 22/06/68.

31 "'Marcha de los pobres' auspicia en Mendoza la CGT, sector Ongaro", Crónica, 26/06/1968.

32 "En Córdoba habló Raimundo Ongaro", Crónica, 28/06/68.

${ }^{33}$ Socialismo Argentino, Movimiento Nacional Justicialista, UCRP, Movimiento Agitación y Lucha (de la UCRP), Juventud Radical, Movimiento Socialista, Movimiento Socialista Revolucionario, Movimiento Nacional de Recuperación, Juventud Comunista, Movimiento de la Liberación Nacional, Democracia Cristiana, Partido Socialista de la Izquierda Nacional, Vanguardia Popular Socialista, Partido Revolucionario de los Trabajadores, Integración Nacional (de la UCRP), Partido Comunista, Comité Nacional de Recuperación Revolucionaria, Partido Socialista Argentino, Vanguardias Populares, Socialismo de Izquierda Nacional, Ateneo Hipólito Yrigoyen, Juventud Revolucionaria Peronista, Movimiento de Liberación Nacional, Juntas de Acción Nacional Justicialista y Acción Revolucionaria Peronista. La Razón, varias ediciones de junio de 1968. También se plegaron otras agrupaciones sindicales que no formaban parte de la CGTA.
} 
Este evento marcaría el comienzo del progresivo distanciamiento de la CGT de los Argentinos de Jerónimo Remorino -por entonces delegado personal de Perón- y de Ricardo Balbín -líder de la UCRP-. ${ }^{34}$ Remorino veía frustrados sus planes de manejar el entramado político que en la central Paseo Colón se articulaba entre los representantes gremiales, la UCRP vinculada a Illia, los sectores estudiantiles y la clase media. Incluso envió su renuncia a Madrid, esperando un gesto del líder exiliado que disciplinara la conducción de Ongaro. Balbín, por su parte, consideraba que la cercanía de los radicales con la central combativa hacia peligrar sus contactos con un sector de la FFAA -contrario a la fracción gobernante- que intentaba impulsar un nuevo golpe de Estado para derrocar a Onganía. ${ }^{35}$

Sí bien en los meses siguientes las tensiones entre el secretariado general de la central combativa con los máximos referentes locales del peronismo y el radicalismo continuaron -una cuestión sobre la que volveremos-, la proyección política de la CGTA como articuladora de las demandas populares se fortaleció en el interior del país a través del trabajo realizado por las regionales sindicales de Córdoba, Rosario, Mendoza y Tucumán.

\section{De la huelga petrolera al Cordobazo}

Durante el mes de agosto de 1968 se realizó el primer encuentro entre la central sindical opositora, las formaciones guerrilleras y las organizaciones juveniles y estudiantiles del peronismo, en la cual se daría la formación del Peronismo Revolucionario (PR). ${ }^{36}$ No obstante, un mes más tarde, se produjeron una serie de eventos que interferirán en la consolidación de la CGTA como articuladora del frente de masas que desde sus inicios buscó articular. La muerte de John William Cooke, el jueves 19 de septiembre de 1968, coincidió con la detención del foco guerrillero de las Fuerzas Armadas Peronistas (FAP) en la localidad de Taco Ralo, provincia de Tucumán. ${ }^{37}$

Por otro lado, la confirmación de Remorino como delegado personal de Perón -luego de haber presentado su renuncia ante la imposibilidad de controlar el curso que adoptaba la central combativa- obturaba los avances políticos de la CGTA en su relación con los sectores opositores a la dictadura, en especial el ala combativa del movimiento peronista, como también grupos

\footnotetext{
34 "Hacia dónde va el gobierno", Primera Plana, 9/05/68, p. 14.

35 "El cerco se cierra", Primera Plana, 24 de julio de 1968, p. 21.

${ }^{36}$ Esta reunión se desarrolló en dos jornadas, a la segunda de las cuales asistió Cooke. Allí se decidió apoyar todas las formas de lucha, incluida la armada y la edición del periódico Con Todo, bajo la dirección de Bernardo Alberte, ex delgado de Perón (Dawyd, 2011).

${ }^{37}$ La Razón, 19/09/68, p. 16. Los detenidos contaron con la asistencia legal de los abogados de la CGTA.
} 
políticos vinculados con organizaciones de izquierda, católicos postconciliares, y agrupaciones estudiantiles. La participación de estos actores en la CGTA "provocan desconfianza" en el "frente de Ongaro". ${ }^{38}$ El líder depuesto, desde las gestiones de Alberte como su emisario local, intentaba forjar una alianza con la UCRP. En ese contexto, Remorino también resultaba impotente en el intento de concitar las adhesiones necesarias para organizar el frente político que Perón buscaba impulsar con el Partido Radical, en tanto las bases juveniles de esa fuerza política rechazaban cualquier acuerdo político con el peronismo por fuera de la CGTA. ${ }^{39}$

El fortalecimiento político de la central obrera con fuerzas distintas al peronismo también incidió en la reunión que mantuvieron Vandor y Perón, en setiembre del '68. Es de destacar que el líder metalúrgico había sido expulsado del peronista en enero de 1966 cuando intentó disputarle al expresidente la dirección del Movimiento Justicialista. No obstante, en esta coyuntura, el exmandatario confió al dirigente de la UOM el llamado a la unidad del movimiento obrero organizado y del peronista que debía expresarse en la unificación de la CGT y en las "62 organizaciones". La intención era, entonces, neutralizar el potencial político y sindical que la central combativa iba gestando, y que parecía estar por fuera de la órbita de control de Perón.

En ese marco de situación, Rodolfo Walsh realizaba un análisis de coyuntura en los siguientes términos:

“Vandor parecía triturado entre la ofensiva de la CGT rebelde y una momentánea cuarentena impuesta por el gobierno. Acudió entonces a España y Perón lo reflotó con la consigna de 'unidad'. Ningún otro hecho político podía resultar tan paralizante en ese momento para la CGT Opositora. Ongaro debió viajar a Madrid para componer lo que fuera posible, mientras en Ensenada se desencadenaba la huelga petrolera" (Walsh, [1968] 2007b: 161).

Esa huelga fue el conflicto obrero más relevante del período. La protesta fue iniciada por más de 7.000 trabajadores petroleros de las localidades de La Plata, Berisso y Ensenada el 25 de septiembre de 1968, en rechazo al aumento de

\footnotetext{
${ }^{38}$ La Razón, 18/07/68, p. 12.

39 La Juventud Radical conformó un Comité Organizador en el que participaron las agrupaciones Agitación y Lucha, FRAGUA, C. Larralde e H. Yrigoyen. El fin consistía en organizar acciones primero en Capital Federal, para luego expandir las actividades en Córdoba y Tucumán, dirigidas a explicitar su rechazo a la salida electoral, y expresando que el Partido Radical “debe apoyar los objetivos de la CGT de los 'argentinos' de acuerdo con el manifiesto del 1ro de mayo de 1968", y "apoyar la coincidencia con los movimientos de liberación nacional condenando el genocidio yanqui en Vietnam y la agresión soviética en Checoslovaquia". La Razón, 1/09/68, p. 14.
} 
la jornada laboral (de 6 a 8 horas), la modificación del régimen jubilatorio para el personal marítimo, y la nueva ley de hidrocarburos. Estos reclamos se reconfiguraron como un enfrentamiento global a la dictadura de Onganía ante la intransigencia de las autoridades a los requerimientos obreros, y la falta de representatividad de Adolfo Cavalli, secretario general del Sindicato Unido de Petroleros del Estado (SUPE), enrolado en la CGT Azopardo. Los obreros en lucha de la regional La Plata del SUPE adhirieron a los planteos de la CGTA, única central obrera que se apoyó e impulso las medidas de fuerza de los trabajadores petroleros.

En el Semanario, además de informar los pormenores que originaron el conflicto, se comunicaban las acciones que la central impulsaba en adhesión a los reclamos de los obreros en lucha. ${ }^{40}$ Además, se exhortaba a los militantes sindicales y a "los partidos populares, cuyas plataforma incluyen la defensa del petróleo," a "comprender que ésta es una instancia decisiva de la supremacía nacional; movilizar todas sus fuerzas y lanzarlas en apoyo de los trabajadores en huelga", resignificando la protesta de los trabajadores petroleros en función de una relectura del conflicto que lo aunaba con la defensa del patrimonio nacional. ${ }^{41}$ En las páginas de este periódico también se publicaba un póster a página completa en donde, además de informar los motivos de la medida de fuerza, se llamaba a "trabajadores, estudiantes, partidos populares y todos los sectores de la Nación" a manifestar su solidaridad con la causa de los trabajadores en lucha, y a participar de la "Jornada nacional en defensa del petróleo," a desarrollarse desde las 0 hs. del 15 de octubre de 1968. ${ }^{42}$ Asimismo, se planteaba que "cada gremio y cada delegación regional debe desde ya manifestar por los más diversos medios orgánicos de acción a su alcance, incluso medidas de acción directa, su solidaridad con los trabajadores petroleros en conflicto". ${ }^{43}$ Tal como había sucedido con los actos del 1ro de mayo y del 28 de junio, la movilización terminó siendo reprimida por las fuerzas de seguridad, resultando detenidas más de 360 personas. ${ }^{44}$

Las convocatorias antes mencionadas fueron acompañadas de crónicas en donde era denunciado el comportamiento espurio de la dirección gremial del SUPE en relación con las medidas de fuerza tomadas por los trabajadores petroleros. Esas denuncias, a su vez, reforzaban la negativa del secretariado de la central "Paseo Colón" de acatar el llamado a la unidad de la CGT ordenado por Perón en septiembre de 1968. La dirigencia combativa consideraba que:

\footnotetext{
40 Semanario CGT, núm. 21, 19/09/1968, p. 5; "Nuevo despojo petrolero," Semanario CGT, núm. 22, 26/09/1968, p. 1; “SUPE,” Semanario CGT, núm. 22, cit., p. 3.

${ }^{41}$ Semanario CGT, núm. 23, 3/10/68, p. 1.

42 Semanario CGT, núm.23, cit., pp. 3-4.

43 “Ganar la calle el 15," Semanario CGT, núm.24, 20/10/1968, p. 1.

44 "La ola represiva”, Semanario CGT, núm. 26, 24/10/68, p. 2.
} 
“Jamás podrá haber unidad con elementos colaboracionistas que como Adolfo Cavalli abandonan a los trabajadores en huelga [...]. Con ese núcleo de colaboracionistas nunca será posible ninguna clase de entendimiento, porque ellos se lavan las manos y olvidan sus deberes con la patria, hoy agraviada por la entrega del petróleo a los monopolios." 45

Por otro lado, comenzaban a explicitarse en el periódico, las tensiones emergentes entre los dirigentes gremiales que integraban la CGTA respecto al apoyo que darían sus gremios al conflicto de los trabajadores petroleros. En esas discusiones se filtraba nuevamente, la cuestión del llamado a la unidad del movimiento obrero organizado. ${ }^{46}$ No obstante, en la publicación se enfatizaba la posición de intransigencia sostenida por la conducción de Ongaro:

"Nosotros estamos dispuestos a esas formas de lucha que son las movilizaciones populares, porque las creemos las más eficaces. Pero no descartamos ninguna otra. Todas son ortodoxas, cuando se lucha por la liberación. [...] La alternativa que surge desde el 28 de marzo es ésa. A nosotros nos toca hacer de montoneros, como dicen algunos, de guerrilleros como dicen otros y no hay otra salida." ${ }^{47}$

En esta declaración se presentan algunas cuestiones referidas a la interpretación que la conducción de la CGTA realizaba del conflicto petrolero. Por un lado, la huelga era considerada como expresión de las luchas populares $\mathrm{y}$, por lo tanto, ameritaba la participación de la central aun cuando el SUPE no adhería formalmente a la central. Es decir, entendían que las reivindicaciones de los trabajadores petroleros excedían los reclamos estrictamente laborales, ya que en ellas subyacía una causa determinante para la defensa de la soberanía argentina, y expresaba una instancia de las luchas por la liberación nacional. Estas consideraciones resignificaban el sentido de las prácticas y de los discursos que desde la CGT "Paseo Colón" se emitían, y que la diferenciaban de las posiciones sostenidas por los sindicalistas de la CGT Azopardo.

A pesar de estas consideraciones, y de las adhesiones que la huelga recibió de otros trabajadores petroleros del país, ${ }^{48}$ el conflicto terminó con una derrota, que se plasmó en el despido de más de dos mil trabajadores, la intervención de los gremios que participaron en la protesta, $^{49}$ y el

\footnotetext{
45 "Cavalli: traidor, botón y mentiroso," Semanario CGT, cit., p. 2.

46 "Una disidencia," Semanario CGT, núm. 24, 20/10/68, p. 4.

47 "¿Esperar qué?", Semanario CGT, núm. 24, 20/10/1968, p. 5.

48 "Mendoza: paran los petroleros", Semanario CGT, núm. 26, 24/10/1968, p. 1.

49 "Petroleros: Cómo terminó la huelga", Semanario CGT, núm. 32, 5/12/1968, p. 3.
} 
fortalecimiento del llamado a la unidad de la CGT realizado por Perón. ${ }^{50}$

Los resultados negativos de la huelga alimentaban los argumentos del vandorismo respecto a la necesidad de unificar la CGT. Los referentes de esa tendencia sindical señalaban que la derrota de los petroleros se debía a la división del movimiento obrero organizado. Un reclamo que se fortalecía, además, por el apoyo expreso de Perón al liderazgo de Vandor, lo cual debilitaba las proyecciones de la CGTA.

No obstante, el secretariado general de la CGT Paseo Colón intentó contener el éxodo de gremios que progresivamente abandonaban el proyecto sindical y político de la central combativa. Durante los meses siguientes los viajes de Ongaro a distintas regiones del país se multiplicaron, tal vez como una manera de atenuar los daños colaterales que el fracaso de la huelga petrolera había ocasionado en un contexto en el que se posicionaba en rebeldía ante la orden de Perón de confluir en una sola CGT. En el mes de enero de 1969 participó del Congreso de Organizaciones Revolucionarias que se realizó en la Provincia de Córdoba. ${ }^{51}$ Semanas más tarde recorrió varios ingenios azucareros en Tucumán, y reclamó su reapertura, el pago de jornales e indemnizaciones. En esa provincia mantuvo reuniones con diversas delegaciones gremiales y estudiantes universitarios. ${ }^{52}$ En el mes abril se apersonó en la localidad santafesina de Villa Ocampo para solidarizarse con sus habitantes luego de la pueblada que forzó la renuncia del intendente, y participó de las manifestaciones organizadas por los trabajadores azucareros despedidos. Para la prensa, la visita de Ongaro en el lugar significó "una carta de esperanza para que la proclamada 'Marcha del Hambre' con la adhesión de Villa Guillermina, Villa Ana, la Gallareta y otras poblaciones del norte santafesino tuviera éxito." Posteriormente, encabezó la manifestación que los obreros del ingenio ARNO realizaron por las calles del pueblo. ${ }^{53} \mathrm{Al}$ momento de decir unas palabras ante la multitud expresó que “[e]l gobierno es el que rompe el pacifismo. Nosotros tenemos que defendernos de la violencia de Onganía". Además, planteó que "[1] a caducidad del sistema alcanza a casi todas las instituciones que actúan dentro de él. Las mismas instituciones que dicen oponerse colaboran en los hechos para que se mantengan las cosas como están." Estas muestras de solidaridad con las luchas que las bases obreras desarrollaban en distintos puntos del país, además de poner en evidencia las perniciosas consecuencias que tenían las políticas económicas implementadas por la dictadura, eran un

\footnotetext{
50 “Decisiones del Comité Central Confederal”, Semanario CGT, cit., p. 1.

51 "El dirigente gremial Raimundo Ongaro que iba en viaje de Córdoba a Tucumán Apareció en Bahía Blanca diciendo que fue secuestrado", La Razón, 16/01/69.

52 “Tucumán: sorpresiva aparición de Ongaro”, Crónica, 1/02/69; “Nuevas declaraciones formuló un dirigente obrero en Tucumán", La Prensa. 8/02/1969.

53 "Orden de captura contra un sacerdote en rebeldía”, Así, 24/04/69.
} 
intento por consolidar los apoyos de los trabajadores y organizaciones de base en lucha hacía la CGTA en un contexto en que la merma de adhesiones al proyecto sindical y político que lideraba Ongaro parecía flaquear. Fortalecer su presencia en el interior permitió, además de darle mayor visibilidad a los conflictos locales, ampliar el área de influencia de la CGT "Paseo Colón”.

Todo lo cual se potenció en los albores del Cordobazo. La proclama en pos de la "Rebelión de las bases" se ponía en acto a través de trabajadores y estudiantes cordobeses, correntinos y santafesinos que hacían tambalear el cerco represivo de la dictadura militar. En ese contexto, los posicionamientos de la CGTA parecieron resurgir, e incluso publicaciones de gran tirada como Primera Plana, contemplaron en Ongaro al líder de la oposición a la dictadura. ${ }^{54}$ Tomás Eloy Martínez, editor de ese semanario, presentaba los eventos de la siguiente manera:

"Los hechos del 30 de mayo tienden a señalar el surgimiento de una nueva oposición, en la que conviven sectores gremiales, de la Iglesia Católica, estudiantiles y de la llamada izquierda nacional, unidos por encima de las clásicas banderías y de los partidos tradicionales. Esa nueva oposición -quizá un simple germen, o el fruto de una solidaridad circunstancial que se disolverá con rapidez- tiene su cara visible en Raimundo Ongaro, 43 [años], líder de la CGT de Paseo Colón." 55

En esa coyuntura, Ongaro le hacía llegar a Orlando Imas una serie de cartas manuscritas, en las que además de relatar los eventos que se vivían en el país y su actuación en ellos, le solicita que intercediera ante Perón para impulsar el accionar conjunto del movimiento obrero organizado. ${ }^{56}$ En esas comunicaciones, decía estar convencido respecto a que “...aquí se repetirá un 17 de octubre, con nosotros en la calle; con todo lo demás [es decir, con el vandorismo y la rama política pactista] no pasará nada serio. Únicamente nos escucharán cuando nos enojemos y dejemos de emplear la diplomacia con nuestros opresores." 57

En el contexto del Cordobazo la central combativa pareció recomponer su liderazgo como principal núcleo opositor a la dictadura. Las movilizaciones que se desarrollaron en las ciudades de Córdoba y Rosario alentaron el camino

\footnotetext{
${ }^{54}$ Primera Plana, 3 de junio de 1969, p. 1.

55 Primera Plana, 3/06/69, p. 3.

56 "Se estableció una Comisión de Enlace entre las dos CGT centrales, pero los de Azopardo, apenas le propusimos el paro salieron disparando y no se los encuentra por ningún lado. En vez de jugar el paro formidable del 30 de mayo a favor de Perón y del pueblo, se han puesto otra vez con la buena letra a ver si les tiran algún hueso o alguna miserable limosna," Carta de R. Ongaro a O. Imas, 18/06/69, Fondo Presidente Juan D. Perón, AGN.

${ }^{57}$ Carta de R. Ongaro a O. Imas, cit.
} 
a combatir en las calles las iniciativas del onganiato, parecían remitir a los postulados del programa político impulsado por la central. Gordillo ha planteado que la magnitud alcanzada por la protesta que se desarrolló en la capital cordobesa se encontraba en relación con "la existencia de una fuerte cultura de oposición y resistencia [...] agudizada por la labor de la CGT de los Argentinos que rivalizó con la tradición antiburocrática del sindicalismo de Córdoba" (1996: 238).

Sin embargo, estos nuevos bríos terminaron siendo neutralizados por la dictadura tras el asesinato de Augusto Vandor. Este hecho desencadenó una serie de persecuciones a la cúpula sindical de la CGTA y a los sindicatos que la integraban, los cuales terminaron siendo intervenidos. Incluso Ongaro fue encarcelado sospechado de haber participado en el asesinato del líder de la UOM. Desde la cárcel, publicaba una solicitada en la que exclamaba:

"Los estudiantes caídos en Corrientes, Rosario y Córdoba, los curas rebeldes de Santa Fe y Tucumán, los comerciantes que cerraron sus puertas en Villa Ocampo y Cañada de Goméz, los intelectuales, profesionales y militantes que cayeron presos junto a los obreros, los movimientos populares que ansían la liberación demuestran que la alianza propuesta por la CGT de los Argentinos a otros sectores del pueblo era posible, digna y correcta. No olvidaremos jamás esos sacrificios ni dejaremos de promover la lucha conjunta contra la dictadura y un sistema corrompido. Pero la rebelión de las bases no puede quedar confiada al movimiento obrero." 58

Aunque la CGTA continuó funcionando en la clandestinidad, ya no logró concitar los apoyos gremiales y políticos iniciales. Quienes formaron parte de esta experiencia obrera, realizaron un último intento por viabilizar el proyecto político de la central a fines de junio de 1970, a través de la convocatoria al Congreso de la Bases de la CGTA. ${ }^{59}$ En esa reunión Ongaro pregonó por "la abolición de la propiedad privada de los medios de producción y toda forma de dominación cualquiera sea su procedencia". ${ }^{60}$ No obstante, el proyecto de "la rebelión de las bases" continuó vigente en otros entramados políticos vinculados a la izquierda peronista en la que confluyeron varios de los dirigentes que habían participado en esta experiencia. ${ }^{61}$

\footnotetext{
58 "Desde la cárcel, Raimundo Ongaro señala el camino de la Liberación Nacional", Crónica, 26/08/69. Destacado es nuestro.

59 “Congreso de los Compañeros", CGT de los Argentinos, Junio de 1970.

${ }^{60}$ La Razón, 1/07/70, p. 10.

${ }^{61} \mathrm{Al}$ respecto, véase Dawyd (2014)
} 


\section{Conclusiones}

La neutralización de las estrategias sindicales vigentes en la Argentina desde 1958 para tramitar los conflictos entre capital y el trabajo habilitaron la posibilidad de reactualizar el bagaje del sindicalismo combativo para liderar el movimiento obrero organizado en 1968. Esta posibilidad cristalizó en la CGT de los Argentinos, en tanto recogió gran parte de las tradiciones del sindicalismo combativo y las condensó en un programa que remitía a los documentos de La Falda (1957) y Huerta Grande (1962). El proyecto político y sindical que se articuló en torno a la CGT "rebelde" fue el resultado de una acumulación de experiencias que, en el contexto creado por la dictadura de Onganía, se desplegó más allá de los límites de la órbita gremial.

Expresó la necesidad de elaborar nuevas formas de intervención política en un contexto clausurado para actuar dentro de los marcos de la representación partidaria. Allí se crearon discursos y prácticas que intentaron interpelar al conjunto de la ciudadanía para expresar públicamente su rechazo a la dictadura cuando esa posibilidad estaba inhibida. Fue entonces que, parafraseando a Maurice Agulhon (2009) "la política se expresaba allí donde podía hacerlo," y desde 1956, por lo menos, los sindicatos eran para los obreros peronistas el ámbito en donde expresar su identidad política. En el devenir del proceso político que se desplegó desde entonces, tanto los sindicatos como sus dirigentes fueron adoptando distintas formas de actuación política que mutaron en relación con la representación peronista, aunque también en algunos casos, a sus aspiraciones personales de poder.

El elemento diferencial de la experiencia que se desarrolló en torno a la CGTA se encuentra en la propuesta de superar los límites de representación sectorial e incluso partidaria. La omisión al inicio de esta experiencia de la identidad peronista por parte sus dirigentes, se relacionaba con la intención de ampliar los márgenes de adhesión política y social, en tanto se esperaba conformar un entramado político que trascendiera la órbita estrictamente partidaria. La disputa por la dirección del sindicalismo argentino con los otros liderazgos sindicales vigentes durante el período, como la puja hacia el interior del movimiento peronista, intervinieron en la toma de posición política que los líderes de la CGTA se vieron forzados a adoptar fines de septiembre de 1968.

La especificidad de la iniciativa que se configuró en torno a la CGT de los Argentinos se expresó en el intento de articular el descontento social generado por la dictadura más allá del ámbito gremial, e incluso, a nuestro entender, del liderazgo de Perón. Esta última cuestión fue la que operó en el retiro del apoyo que el líder exiliado había depositado en esta iniciativa. A partir de entonces, los frentes de lucha que la central de Paseo Colón debía enfrentar se ampliaron. Por un lado, el gremial, fundamental para articular el accionar político, se fue 
diluyendo en los meses sucesivos a septiembre del '68 tras el acatamiento progresivo de los sindicatos a la propuesta de Madrid de unificar la CGT en torno al vandorismo. El paulatino desmembramiento de la base sindical de la CGT Paseo Colón terminó por provocar el debilitamiento de su propuesta política. Esta última cuestión adquirió carácter dramático luego del asesinato de Vandor, un mes después del Cordobazo. El crimen del líder metalúrgico le otorgó a la dictadura la razón definitiva para desmantelar la CGTA.

No obstante, la incidencia de esta central obrera como espacio de articulación política frente al malestar político y social provocado por el onganiato pervivió en la memoria política de distintos contingentes militantes que se gestaron en los '70, incidiendo significativamente en las tramas políticas y simbólicas de la izquierda peronista como cultura política.

\section{Bibliografía citada}

Acha, Omar (2004). "Sociedad civil y sociedad política durante el primer peronismo", en Desarrollo Económico, Vol. 44, núm.174, pp. 190-210.

Agulhon, Maurice (2009). El círculo burgués, La sociabilidad en Francia, 1810-1848. Buenos Aires: Siglo XXI.

Balvé, Beba (2005). Lucha de calles, lucha en clases. Elementos para su análisis, Buenos Aires: Ediciones R y R.

Bartoletti, Julieta (2011). "La CGT de los argentinos y los dilemas de la izquierda peronista”, en Revista Escuela de Historia, Vol. 10, núm. 2.

Baschetti, Roberto (1997). Documentos de la Resistencia Peronista. 1955-1970. Buenos Aires: de la Campana.

Berrotarán, Patricia; Pozzi, Pablo (1994). Estudios inconformistas sobre la clase obrera. 1955-1989. Buenos Aires: Ediciones Letra Buena.

Brennan, James (1996). El Cordobazo. Las guerras obreras en Córdoba 1955-1976. Buenos Aires: Sudamericana.

Bozza, Juan A. (2001). “El peronismo revolucionario. Itinerario y vertientes de radicalización, 1959-1969”, Sociohistorica, núm. 9/10, pp. 135-169.

(2009). “La voluntad organizada. La CGT de Los Argentinos, una experiencia de radicalización sindical", Anuario del Instituto de Historia Argentina, núm. 9, pp. 179-208.

(2010). “Una voz contra los monopolios CGT. El periódico de la CGT de los Argentinos", Oficios Terrestres, núm. 25.

Caruso, Valeria (2015). “Una experiencia informativa del sindicalismo 
combativo: El Semanario CGT", Trabajos y Comunicaciones, 2da Época, núm. 41, pp. 1-14.

(2015b). "Sindicatos, intelectuales y dictadura en la Argentina durante la década del '60. Perspectivas para un debate historiográfico a partir del caso de la CGT de los Argentinos", Revista Contemporânea, Vol.1, núm. 7.

(2019). "Raimundo Ongaro, un intelectual para la liberación de las bases", Claves. Revista de Historia, Vol. 5, núm. 8, Facultad de Humanidades y Ciencias de la Educación, Universidad de la República, Uruguay.

Chama, Mauricio (2006). “Peronización y radicalización de grupos de abogados en los años sesenta y principios de los setenta. La labor defensista como práctica militante." Cuestiones de Sociología - Revista de Estudios Sociales, núm.3, UNLPPrometeo.

Dawyd, Dario, (2010). “La 'Huelga Santa' de los petroleros de Ensenada. Petróleo, peronismo y política en el 68 argentino", en Basualdo, Victoria [Coord.], La clase trabajadora en la Argentina del siglo XX. Experiencias de lucha y organización. Buenos Aires: Cara o Seca.

(2012). “Del semanario al libro. La escritura de Rosendo en Rodolfo Walsh como construcción del vandorismo en la Argentina del peronismo fracturado". Trabajo y Sociedad. Sociología del Trabajo - Estudios culturales- Narrativas sociológicas y literarias, Vol. 15, núm.18.

(2014). "Corrientes y nucleamientos del sindicalismo opositor peronista. Entre la CGT de los Argentinos y el regreso de Perón, 1970-1973". Revista Quinto Sol. Instituto de Estudios Sociohistóricos. UNLP. Santa Rosa. La Pampa. Vol. 18, núm.18.

Dip, Nicolás. (2017). Libros y alpargatas. La peronización de estudiantes, docentes e intelectuales de la UBA (1966-1974). Rosario: Prohistoria.

Friedemann, Sergio (2014). La Universidad Nacional y Popular de Buenos Aires (1973-1974). Una reforma universitaria inconclusa. Tesis doctoral. Universidad de Buenos Aires, mimeo.

Godio, Julio (2000). Historia del movimiento obrero argentino. La época del sindicalismo peronista (1943-2000). Buenos Aires: Editorial Corregidor.

Gordillo, Mónica (1996). Córdoba en los '60. La experiencia del sindicalismo combativo. Córdoba: Universidad Nacional de Córdoba.

(2003). “Protesta, rebelión, y movilización: de la resistencia a la lucha armada, 1955-1973", Nueva Historia Argentina, Tomo IX. Buenos Aires: Sudamericana.

James, Daniel (1990). Resistencia e integración. El peronismo y la clase trabajadora 
argentina. 1946-1976. Buenos Aires: Sudamericana.

Manzano, Valeria (2017). La era de la juventud en Argentina. Cultura, política y sexualidad desde Perón hasta Videla. Buenos Aires: Fondo de Cultura Económica.

Pulfer, Dario (2018). Aproximación a la trayectoria de Amado Olmos. Buenos Aires: Peronlibros.

Sarlo, Beatriz (2014). Viajes. De la Amazonia a las Malvinas. Buenos Aires, Buenos Aires: Seix Barral.

Schneider, Alejandro (2005). Los compañeros. Trabajadores, izquierda y peronismo. 1955-1973. Buenos Aires: Imago Mundi.

Sotelo, Luciana (2012). "El mundo sindical entre la acción gremial y la acción política. Continuidades y rupturas de la CGT de los Argentinos respecto de las experiencias anteriores." Polhis, año 5, núm. 10, pp. 156-170.

Torre, Juan Carlos (2004). El gigante invertebrado. Los sindicatos en el gobierno, 1973-1976. Buenos Aires: Siglo XXI.

Vertbitsky, Horacio; Sztulwark, Diego (2018). Vida de perro: Balance político de un país intenso, del 55 a Macri. Buenos Aires: Siglo XXI Editores Argentina.

Viano, María Cristina (1994). "Recorriendo una experiencia político sindical de los sesenta desde su semanario: la CGT de los Argentinos”. Anuario, núm.16.

Walsh, Rodolfo (2007a) ¿Quién mató a Rosendo? Buenos Aires: Ediciones de la Flor.

de la Flor.

(2007b) Ese hombre y otros papeles personales. Buenos Aires: Ediciones

\section{Periódicos y revistas}

Informes DIL (Buenos Aires) 1968.

La Nación (Buenos Aires) 1968.

La Razón (Buenos Aires) 1968-1970.

Primera Plana (Buenos Aires) 1968-1969.

Semanario CGT (Buenos Aires) 1968-1969.

\section{Documentos}

Carta de R. Ongaro a O. Imas, 18 de junio de 1969, Fondo Presidente Juan D. Perón, AGN 
Prohistoria, Año XXIV, núm. 35, jun. 2021, ISSN 1851-9504

\section{Entrevistas}

Entrevista a Carlos "Pacho" Gaitán, Buenos Aires, 13 de mayo de 2013. 